\title{
A Conceptual Model of Immersive Experience in Extended Reality
}

\author{
Hyunkook Lee \\ (h.lee@hud.ac.uk)
}

Applied Psychoacoustics Lab (APL), University of Huddersfield, HD1 3DH, UK.

\begin{abstract}
The term immersion or immersive is popularly used when describing and evaluating technologies in the area of extended reality (i.e., virtual/augmented/mixed reality). Much research has been conducted on immersion over the last few decades. However, there is still a lack of consistency in how the term is defined in the literature. Presence and involvement are other prominent concepts studied in the field of extended reality. However, there is currently no consensus on their relationship with immersion among researchers. This paper first discusses different dimensions of immersion as well as those of presence and involvement, aiming to resolve potential confusion around the terms and synthesise a relationship among them. From this, a new conceptual model of immersive experience for future studies in extended reality is proposed. The model defines physical presence, social/self presence and involvement as the main high-level attributes that collectively lead to an immersive experience. Each pair of the three attributes shares a common lower-level attribute of sensory, narrative or task/motor engagement, which is an initial step towards the higher-level experience. Plausibility, interactivity and interestingness are defined as the main properties of immersive system and content, each of which is biased by a subjective factor: internal reference, skills/knowledge and personal preference, respectively.
\end{abstract}

Keywords: Immersion, immersive experience, conceptual model, extended reality, presence, involvement 


\section{O INTRODUCTION}

The last decade saw a significant advancement of technologies for virtual reality (VR), augmented reality (AR) and mixed reality (MR), all of which are encompassed in the umbrella term extended reality (XR). In VR, the user is visually and aurally occluded from the physical environment by wearing a head-mount display (HMD) and headphones, whereas in AR, the user interacts with virtual objects superimposed onto the physical environment seen through special glasses or the screen of mobile device. MR blends both VR and AR experiences. Today XR technologies are being adopted in an increasing number of applications, such as games (Carvalho, Soares, Neves, Soares, \& Lins, 2014), audio-visual entertainment (Slater \& Sanchez-Vives, 2016), medicine (Andrews, Southworth, Silva, \& Silva, 2016), tourism (Tussyadiah, Wang, Jung, \& tom Dieck, 2018), education (Freina \& Ott, 2015), etc. It is frequently described that $\mathrm{XR}$ applications aim to provide the user with an immersive experience. In the industry, the term immersive has become a popular marketing term for XR technologies. In academia, however, there has been much debate on the meaning of immersion and the relationship among immersion and other related concepts such as presence and involvement. However, there still exists no standard definition of immersion. Different models tend to use different terms with overlapping meanings or identical terms with slightly different meanings depending on the context. More importantly, there is no global conceptual framework for measuring the level of immersive experience that can be applied in a wide range of $\mathrm{XR}$ applications.

Even though several multidimensional models of immersion have been proposed (e.g., (Arsenault, 2005; Brown \& Cairns, 2004; Calleja, 2007; Ermi \& Mäyrä, 2005; Ryan, 2003)), most of them are specific to the contexts of video games, and therefore it might be difficult to apply them directly in other contexts. It is also found in the literature that terms presence, involvement or engagement are often used interchangeably with immersion, whereas other researchers strictly distinguish them as different concepts. The inconsistency and ambiguity in the terminology could cause confusion in comparing different studies.

From the above background, the present paper aims to define relationships among various concepts related to immersion and integrate them into a general conceptual model of immersive experience. Firstly, Section 1 discusses the multidimensionality of immersion and identify the source of confusion around the term. From this, a standard terminology is proposed for the purpose of consistency. Section 2 briefly explicates the concepts of physical presence, social/self presence and involvement, which are considered as the main underlying 
factors of immersive experience in this paper, and how each concept is related to immersive experience. Based on the discussions provided in Sections 1 and 2, Section 3 proposes and details a conceptual model of immersive experience. The model establishes a relationship among the high-level concepts physical presence, social/self presence and involvement in terms of immersive experience, and identifies the associated properties of immersive system and content as well as potential subjective factors.

\section{$1 \quad$ MULTIDIMENSIONALITY OF IMMERSION}

Although there is still no standard definition of immersion, the general consensus in the literature seems to be that immersion is a multidimensional construct. As summarised in Table 1 , researchers have proposed different dimensions of immersion using various descriptive words, e.g., perceptual and psychological immersion (Lombard \& Ditton, 1997), sensory, imaginative and challenge-based immersion (Ermi \& Mäyrä, 2005), sensory, fictional and systemic immersion (Arsenault, 2005), narrative and ludic immersion (Ryan, 2003), narrative and strategic/tactical immersion (Adams \& Rollings, 2007). However, some of these terms largely overlap in their meanings, and seem to connote the general ideas of either 'presence' or 'involvement', which are explicated in Section 2.1. For example, Biocca and Delaney (1995) defined perceptual immersion as "the degree to which a virtual environment submerges the perceptual system of the user". The same term is used by McMahan (2013) to describe the sensation of being surrounded by a virtual environment (VE), which is also implied in the definition of sensory immersion by Ermi and Mäyrä (2005). These terms commonly describe a passive experience of immersion (Eaton \& Lee, 2019), which is induced by the sensory simulation of a technology. They are also commonly related to the concept of 'presence'. The other immersion terms above describe an active (cognitive) experience of immersion (Eaton \& Lee, 2019). For instance, imaginative immersion (Ermi \& Mäyrä, 2005) and narrative immersion (Adams \& Rollings, 2007; Ryan, 2003) commonly require involvement in the narrative of a content. Challenge-based immersion, ludic immersion, systemic immersion and strategy/tactical immersion are commonly to do with involvement in a challenging task or an activity. In addition, the Oxford Learner's Dictionaries also provide two separate definitions of immersion; (i) "the act of putting somebody/something into a liquid, especially so that they or it are completely covered; the state of being covered by a liquid", and (ii) "the state of being completely involved in something". The first definition is often used as a metaphor for perceptual or sensory immersion, e.g.,(Murray, 1997, pp. 98-99), whereas the second one is essentially a cognitive phenomenon, which does not necessarily require a sensory simulation. 
Table 1. Summary of different immersion terms from the literature.

\begin{tabular}{|c|c|c|}
\hline Immersion terms & Descriptions & Connoted concept \\
\hline $\begin{array}{c}\text { Perceptual (F Biocca \& } \\
\text { Delaney, 1995; McMahan, } \\
\text { 2013) }\end{array}$ & $\begin{array}{l}\text { "the degree to which a virtual } \\
\text { environment submerges the } \\
\text { perceptual system of the user" (F } \\
\text { Biocca \& Delaney, 1995); } \\
\text { The sensation of being surrounded } \\
\text { by a virtual environment } \\
\text { (McMahan, 2013) }\end{array}$ & Presence \\
\hline $\begin{array}{l}\text { Sensory (Ermi \& Mäyrä, } \\
\text { 2005) }\end{array}$ & $\begin{array}{l}\text { The state of being surrounded by } \\
\text { audio-visual stimuli that can } \\
\text { "overpower the sensory information } \\
\text { coming from the real world" }\end{array}$ & \\
\hline $\begin{array}{l}\text { Imaginative (Ermi \& Mäyrä, } \\
\text { 2005) }\end{array}$ & \multirow{3}{*}{$\begin{array}{l}\text { The state of being heavily involved } \\
\text { (cognitively absorbed) in the story } \\
\text { world and by its characters. }\end{array}$} & \multirow{3}{*}{$\begin{array}{c}\text { Involvement } \\
\text { in a narrative of a } \\
\text { content }\end{array}$} \\
\hline Fictional (Arsenault, 2005) & & \\
\hline $\begin{array}{c}\text { Narrative (Adams \& Rollings, } \\
\text { 2007; Ryan, 2003) }\end{array}$ & & \\
\hline Ludic (Ryan, 2003) & \multirow{4}{*}{$\begin{array}{l}\text { The stage of being heavily involved } \\
\text { in a challenging task or an activity } \\
\text { that requires mental or/and motor } \\
\text { skills. }\end{array}$} & \multirow{4}{*}{$\begin{array}{l}\text { Involvement } \\
\text { in a task or an } \\
\text { activity }\end{array}$} \\
\hline $\begin{array}{c}\text { Challenge-based (Ermi \& } \\
\text { Mäyrä, 2005) }\end{array}$ & & \\
\hline Systemic (Arsenault, 2005) & & \\
\hline $\begin{array}{c}\text { Strategic and Tactical } \\
\text { (Adams \& Rollings, 2007) }\end{array}$ & & \\
\hline
\end{tabular}

Several researchers attempted to provide standalone definitions of immersion (e.g., (Agrawal, Simon, Bech, Bærentsen, \& Forchhammer, 2020; Murray, 1997; Witmer \& Singer, 1998) However, such definitions tend to be biased towards only one dimension of immersion. For example, Witmer and Singer (1998) defines immersion as "a psychological state characterized by perceiving oneself to be enveloped by, included in, and interacting with an environment that provides a continuous stream of stimuli and experiences". Whilst this definition mainly describes the perceptual aspect of the experience provided by the system, the cognitive aspect of the experience is not clearly implied. Agrawal et al. (2020), on the other hand, define immersion as "a phenomenon experienced by an individual when they are in a state of deep mental involvement in which their cognitive processes (with or without sensory stimulation) cause a shift in their attentional state such that one may experience disassociation from the awareness of the physical world". Although this definition could be applied in a wide scope including when there is no sensory input is involved (e.g., immersion in daydreaming or 
reading a novel), it primarily focuses on the cognitive facets of immersion. The disassociation from the physical world mentioned in their definition is based on the concept of narrativeinduced transportation ("immersion or absorption into a narrative world" (Green \& Brock, 2000)) rather than that of a technology-induced transportation (i.e., telepresence (Minsky, 1980) or physical presence (Biocca, 1997).

Murray (1997, pp. 98-99) describes immersion as follows: "The experience of being transported to an elaborately simulated place is pleasurable in itself, regardless of the fantasy content. We refer to this experience as immersion. Immersion is a metaphorical term derived from the physical experience of being submerged in water. We seek the same feeling from a psychologically immersive experience that we do from a plunge in the ocean or swimming pool: the sensation of being surrounded by a completely other reality, as different as water is from air, that takes over all of our attention, our whole perceptual apparatus". This definition connotes the concept of physical presence (Biocca, 1997) (i.e., being transported into and surrounded by a VE), but also suggests a "pleasurable" experience as a cognitive outcome of immersion. As will be discussed more in Section 2.3, however, immersive experience is not necessarily pleasurable. The element of pleasure seems to be more related to the concept of flow (Mirvis, 1991).

As opposed to the aforementioned studies that regard immersion as perceptual or/and cognitive experiences, Slater (2003) asserts that immersion is simply "what the technology delivers" to provide the user with a sensation of being there. He equates the level of immersion to the level of the technology; the more advanced, the more immersive (Slater, 1999). This notion has been followed by other researchers studying presence (e.g., (Berkman \& Akan, 2019; Cummings \& Bailenson, 2016; Diemer, Alpers, Peperkorn, Shiban, \& Mühlberger, 2015; Ragan, Sowndararajan, Regis, \& Bowman, 2016)), but also been criticised by those who assert that immersion as a psychological experience resulting from a technological process ((Agrawal et al., 2020; Witmer \& Singer, 1998)).

To avoid potential confusion about the meaning of immersion, it is proposed here to standardise the terminology, such that we explicitly say "immersive experience" and "immersive system" when referring to immersion as an experience and immersion as a technological process, respectively. This would clarify the cause-and-effect relationship between system (independent variable) and experience (dependent variable). If one says "a higher level of immersion leads to a stronger sense of being there", it would be unclear what 
immersion exactly means here. If it meant a technological process, it would be clearer to say that "a more advanced immersive system provides a stronger sense of being there". If the term was used to refer to an experience, it would be less confusing to say that "a higher level of immersive experience leads to a stronger sense of being there". However, this statement might still be confusing. Immersive experience in this statement is described as an independent variable for the sense of being there (i.e., physical presence), which is a dependent variable, but the opposite might make more sense. Physical presence can be what an immersive system aims for, but is not an ultimate outcome of immersive experience. It is argued that immersive experience is a higher-level concept that necessitates mental or/and physical involvement in a task or an activity as well as physical presence, as will be discussed further in the following sections. Hence, it is considered to be more correct to say that "a strong sense of physical presence leads to a high level of immersive experience".

\section{UNDERLYING CONCEPTS of IMMERSIVE EXPERIENCE}

\subsection{Presence}

In the literature, the terms presence and immersion are often used as synonyms (e.g., (Lombard \& Ditton, 1997; McMahan, 2013; Murray, 1997, pp. 98-99)), whereas some researchers distinguish them as separate concepts (e.g., (Agrawal et al., 2020; Diemer et al., 2015; Jennett et al., 2008; Nilsson, Nordahl, \& Serafin, 2016)). Furthermore, researchers in the field of the so-called "presence research" often consider immersion as a lower-level concept or a determinant of presence (e.g., (Berkman \& Akan, 2019; Cummings \& Bailenson, 2016; Diemer et al., 2015; Ragan et al., 2016; Witmer \& Singer, 1998)), whereas some others tend to regard immersion as a higher-level concept (e.g., (Brown \& Cairns, 2004; Ermi \& Mäyrä, 2005; Zhang, Perkis, \& Arndt, 2017)). As with immersion, presence is a multidimensional construct. To conceptualise the relationships between presence and immersive experience in this study, the typology of presence is first discussed. Arguably, the most widely cited typology of presence is Biocca (1997)'s three types of presence: physical, social and self presence.

Physical presence is generally defined as the sense of being there (in a VE). Terms with a similar meaning include telepresence (Minsky, 1980), spatial presence (Hartmann et al., 2016; Schubert, Friedmann, \& Regenbrecht, 2001) and place illusion (Slater, 2009). This type of presence is often understood simply as a consequence of sensory simulation provided by an immersive system; the more advanced the system is, the higher the level of presence is ((Biocca, 1997; Ermi \& Mäyrä, 2005; Slater, 2003; Slater \& Wilbur, 1997; Steuer, 1995; Witmer 
\& Singer, 1998)). In this sense, physical presence can be considered to be equivalent to sensory immersion (Ermi \& Mäyrä, 2005) or perceptual immersion (Biocca \& Delaney, 1995).

However, as Schubert et al. (2001) argue, physical presence is not just a hard-wired perceptual phenomenon that occur immediately from sensory information, but also involves a cognitive process to make sense the VE as a physical reality. Brown and Cairns (2004) suggest that presence is a state of total immersion (as an experience), which is achieved through engagement and engrossment in a task or activity. From a questionnaire survey on presence, Witmer and Singer (Witmer \& Singer, 1998) identified that selective attention as well as sensory fidelity determined the level of presence. This is supported by Schubert et al. (Schubert et al., 2001)'s finding that the two primary factors of presence were spatial constructive and attention. Literature also suggest that physical presence can occur without any sensory stimulation. For example, it would be possible to experience a sensation of presence through the narrative of the content (i.e., narrative engagement (Busselle \& Bilandzic, 2009), narrative transportation (Green \& Brock, 2000)).

Whilst it is acknowledged that the role of cognition must be considered when explaining presence, it is argued that, in the context of technology-mediated immersive experiences in $\mathrm{XR}$ applications, the more advanced the immersive system, the more likely it would reduce the amount of cognitive effort required for physical presence. In the real world, a mental model of the surrounding environment is automatically and instantly generated from a sensory pattern recognition mechanism (Biocca, 1997). Furthermore, the sensory perception of the physical environment changes depending on the bodily movement (i.e., sensorimotor contingencies (SMCs)) (O'Regan \& Noë, 2001). Therefore, in an XR application, if the immersive system were able to support SMCs that are necessary for a plausible simulation of a PE, a mental model of the VE would likely be created more quickly and effectively than when using a lower-level system. Sheridan (1992) asserts that the ability to physically and realistically interact with the VE (e.g., switching on and off a fan in a virtual room) is an important factor for physical presence. Heeter (1992) refers to this type of presence 'environmental presence'.

Social presence, defined as the sense of being together and interacting with another intelligence (Biocca, 1997; Heeter, 1992), is considered to be both perceptual and cognitive experiences. Biocca (1997) states that the level of social presence is determined by "the degree to which the user feels access to the intelligence, intentions, and sensory impressions 
of another"; it is minimum when the technology user can simply sense the presence of another intelligence, which is similar to the original concept of co-presence (Goffman, 1963). The perceptual stage of social presence can be understood as a type of sensory immersion (e.g., the sensation of being surrounded by other intelligences within the same virtual environment). For instance, consider an application where one can virtually conduct an orchestra in VR. Being surrounded by realistically-simulated musicians on a concert hall stage will be a lowlevel social presence experience. The level of social presence will become higher if the virtual conductor is able to interact with the musicians at an intelligent level where the conductor's musical intention expressed through motion is reflected on the musician's performance. This is related to the concepts of challenge-based immersion (Ermi \& Mäyrä, 2005) and narrative immersion (Adams \& Rollings, 2007; Ryan, 2003). From a systematic review, Oh, Bailenson, \& Welch (2018) found that interactivity as well as the audio-visual qualities of the system were important predictors for social presence. Interactivity is also considered to be a property of an immersive system that could induce involvement.

Self presence (Biocca, 1997), also referred to as personal presence (Heeter, 1992), represents a user's mental model of himself or herself inside the VE and the physiological and emotional states (i.e., virtual self is experienced as the actual self in either sensory or nonsensory ways (Lee, 2004)). As with social presence, self presence is a phenomenon occurring in both perceptual and cognitive domains and distinct levels. Based on Damasio (1999)'s self-map framework, Ratan (2012) divides self presence into three levels: proto-self (body-level), core-self (emotion-level), and extended-self (identify-level). Proto-self leads to core-self, which allows for extended-self (Ratan, 2012). Proto-self presence is about how realistic the representation of the virtual self is, which is related to the technological level of immersive system. Again, the original definition of sensory immersion could be further expanded to incorporate proto-self presence, e.g., the sensation of the full or part of the virtual self's body being surrounded by virtual intelligences and environment. Core-self is induced through social interactions with mediated objects, which leads to a social identity of the self (extended-self) (Ratan, 2012). Recalling the virtual orchestral conducting example from above, the conductor's extended-self will be boosted maximally when there is a high level of intelligent or/and emotional communion with the virtual musicians in performing a musical piece. This can be also linked with challenge-based immersion. Hence, it is suggested that social presence and self presence are closely inter-related, and from this both concepts are included as a key component in the immersive experience model proposed in Section 3. The concepts 
of social and self presence are particularly relevant in XR applications, where the interactivity of the system and content is paramount.

\subsection{Involvement}

The term involvement is often described as a necessary condition for cognition-based immersion (Ermi \& Mäyrä, 2005; Lombard \& Ditton, 1997; Ryan, 2003) or presence (; Lombard \& Ditton, 1997; Witmer \& Singer, 1998). Witmer and Singer [11] defines involvement as "a psychological state experienced as a consequence of focusing one's energy and attention on a coherent set of stimuli or meaningfully related activities and events". Calleja (2007) specifies six dimensions of involvement in the context of digital games: tactical, performative, affective, shared, narrative and spatial. Tactical involvement is related to all kinds of decision making and interaction with the rules of the games as well as with other players. Performative involvement is about execution of the decision made from tactical involvement. Affective involvement represents the mood and emotional states resulting from the design and aesthetics of games. Shared involvement is to do with the ability to locate and interact with other intelligences. Narrative involvement is the extent to which the user is engaged with the designed and personal narratives of the game. Finally, spatial involvement is related to localising oneself and other players in the game area beyond the visible screen using a mental map. Calleja (2007) ultimately considers these dimensions of involvement as the determining factors of "incorporation" in gameplay, which is his own concept similar to immersion.

Brown and Cairns (2004) established a ground theory, in the context of digital games, suggesting that total immersion occurs through two steps of involvement: engagement and engrossment. Engagement is the minimum level of involvement with a game, which occurs when the gamer decides to spend time and energy to play it. This depends on the gamer's personal preference as well as game controls. The next level of involvement is that the gamer become engrossed in the gameplay to a point where he or she pays a full attention 1and becomes emotionally attached to the game. The final stage is total immersion, where the gamer is completely dissociated from the physical reality and absorbed in the game world. Brown and Cairns equates total immersion to presence. However, in contrast to the concept of sensory or perceptual immersion (Biocca, 1997), the conceptualisation of immersion by Brown and Cairns (2004) and Calleja (2007) have a heavier focus on involvement rather than the sensation of being surrounded by the VE. This seems to be because their study was conducted specifically in the context of games, where the content has an active nature requiring the user's mental and physical efforts in interactive gameplay. 


\section{$2.3 \quad$ Flow}

Csikszentmihalyi (Csikszentmihalyi, 1990) developed a concept of "flow" to describe an optimal experience for happiness. To experience a flow state, there are eight conditions to meet: Tasks with a reasonable chance of completion, clear goals, immediate feedback, deep involvement, sense of control, loss of self-consciousness and alteration of the concept of time. These seem to have some conceptual overlap with psychological immersion (Lombard \& Ditton, 1997), challenge-based immersion (Ermi \& Mäyrä, 2005) and narrative immersion (Ermi \& Mäyrä, 2005; Ryan, 2003). They all necessitate involvement and result in a sensation of being dissociated from the physical world. Michailidis et al. (Michailidis, Balaguer-ballester, $\mathrm{He}, \&$ Balaguer-ballester, 2018) argue that total immersion by Brown and Cairns (Brown \& Cairns, n.d.) is essentially an experience of a deep flow state. On the other hand, some other researchers distinguish immersion from flow (Frochot, Elliot, \& Kreziak, 2017; Jennett et al., 2008; Sanders \& Cairns, 2010). It is important to note that the key element of the optimal experience in the flow concept is enjoyment. As Jennett et al. (Jennett et al., 2008) point out, immersion is not necessarily an enjoyable experience. As an outcome of immersive experience, one can develop negative emotions such as anxiety and frustration, whereas a flow experience will always positively influence the mindset. For instance, consider playing a boxing game in VR. The player might be highly present and involved in the game, but it would likely be an unpleasant and frustrating experience if he or she lost it after having been brutally beaten. This is why "tasks with a reasonable chance of completion" and "sense of control" are necessary conditions to experience a flow state, whereas they are not always necessary for feeling immersed. Based on this discussion, flow is not included in the immersive experience model proposed in the next section.

\section{PROPOSED MODEL OF IMMERSIVE EXPERIENCE}

\subsection{Model Overview}

As discussed above, immersive experience (IE) has multidimensional nature. Although previous models of immersion use a number of different adjectives to describe different types of IE, they tend to connote the underlying concepts of physical presence, social/self presence or involvement. This section proposes a global and simple conceptual model of IE to synthesise the hierarchical structure of the high-level and low-level factors of IE and their relationships with the properties of immersive system and content as well as potential bias factors. 
Figure 1 illustrates the model. As proposed in Section 1, the term "immersive experience (IE)" is used to avoid a potential confusion with "immersion" that is often used to mean a technological process. In the conceptual hierarchy, IE is the highest-level dependent variable, whilst the "immersive system (IS)" and the "Content" are the independent variables. There are three high-level dependent variables that are associated with IE: physical presence (PP), social or/and self presence (SP) and involvement (INV). Each of the three attributes has overlapping sub-components: sensory engagement between $\mathrm{PP}$ and $\mathrm{SP}$, narrative engagement between PP and INV, and task/activity engagement between INV and SP. These attributes are selectively related to the three main properties of IS and Content: plausibility for PP and SP, interestingness for PP and INV, and interactivity for INV and SP. Plausibility, interestingness and interactivity are influenced by subjective factors: internal reference, personal preference, and skills/knowledge, respectively. These are considered as confounding variables.

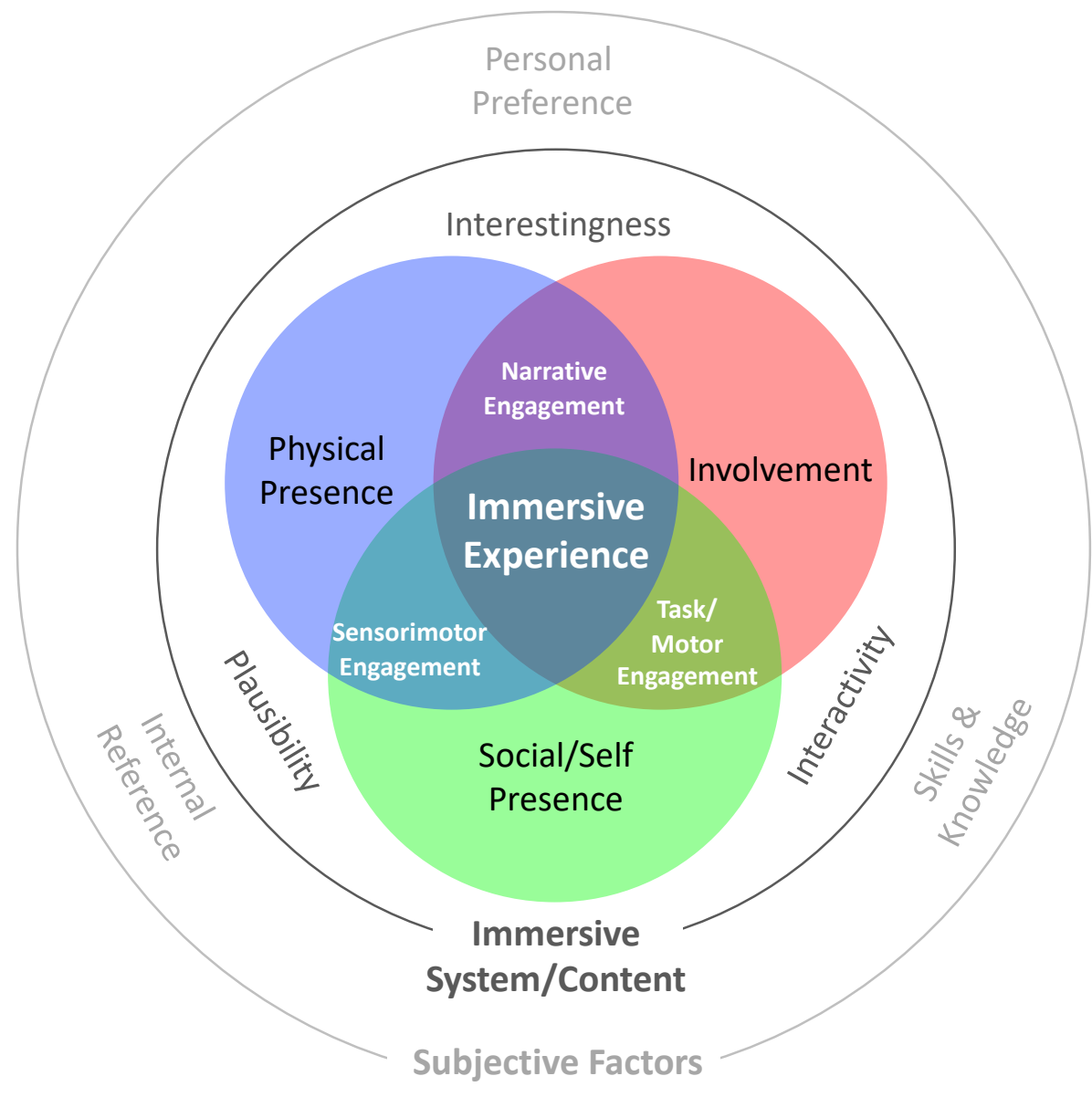

Figure 1. Proposed conceptual model of immersive experience (IE) in extended reality. 
Note that in the scope of the proposed model, IE does not necessarily require all of PP, SP and INV to occur together. Each of the dimensions can independently create IE, but the overall level of IE (OLIE) will become stronger if more of these dimensions contribute collectively. This is further discussed with example scenarios in Section 3.5.

\subsection{Presence and Involvement as the Main Attributes of IE}

The rationales to include PP, SP and INV as the high-level attributes of IE are explained as follows. Firstly, the definitions of presence discussed in the previous section are connoted in those of various immersion terms. For example, the perceptual aspect of PP is implied in the definitions of perceptual immersion (F Biocca \& Delaney, 1995; McMahan, 2013), sensory immersion (Ermi \& Mäyrä, 2005) and spatial immersion (Zhang et al., 2017), whilst the cognitive aspect is incorporated in the definitions of imaginative immersion (Ermi \& Mäyrä, 2005) and narrative immersion (Ryan, 2003). They all are to do with an experience of being physically transported from the PE into a VE in either sensory or nonsensory ways, and the highest level of such experiences is that the user is completely dissociated from the PE (e.g., "the perceptual illusion of nonmediation" (Lombard \& Ditton, 1997)).

Furthermore, SP can be considered as a possible scenario of challenge-based immersion (Ermi \& Mäyrä, 2005) and ludic immersion (Ryan, 2003), where a virtual self is engaged in a certain activity or task with other virtual intelligences or objects. In the current model, social presence and self presence are considered as inter-related concepts, especially in the context of interactive XR applications. As discussed in Section 2.1, the basic level of both types of presence is sensory engagement. Higher levels of both experiences are achieved through social interactions in a task or activity at an intelligent or/and emotional level (Biocca, 1997; Ratan, 2012). Based on (Ratan, 2012), although proto self presence does not require other people or objects in the VE, core and extended self presence is closely associated with social presence. Therefore, whilst self presence does not necessarily induce social presence, it is hypothesised that a higher level of social presence (through interactions) foster a higher level of self presence.

As with presence, INV is an underlying concept for various immersion terms previously defined. In particular, some of Calleja's concepts of INV introduced earlier are connoted in the definitions of narrative immersion (Ryan, 2003) (narrative involvement), challenge-based immersion (Ermi \& Mäyrä, 2005) (tactical and performative involvement) and imaginative immersion (Ermi \& Mäyrä, 2005) (spatial involvement). A similar term to INV is cognitive 
absorption, defined as "a state of deep involvement with software" (Agarwal \& Karahanna, 2000). This essentially refers to a degree of involvement, as in the term engrossment used by Brown and Cairns. Therefore, INV is considered to be a more general term to use in the IE model.

The proposed IE model considers that PP, SP and INV are at the same level of the conceptual hierarchy. Slater (Slater, 2003) claims that PP and INV are orthogonal concepts, with the former being facilitated by Immersive System and the latter being related to Content. However, it is argued here that they influence each other and collectively contribute to IE. This is supported by the findings of several studies. In games, INV was an important factor that determines the level of presence (Brown \& Cairns, 2004.; Calleja, 2007; Heeter, 1992; Witmer \& Singer, 1998). Ryan (2003) claims that in virtual reality a strong physical presence could develop an intimate relation to the narrative of the content as well as a sense of being there. Furthermore, Slater (2009) argues that the sensation of being in a plausible VE leads to the user's realistic responses to sensory stimulation within the environment. It is possible that this can also foster natural interactions with virtual objects and eventually leads to a deep state of INV in the activity. As an example, listening to a realistic three-dimensional (3D) recording of an orchestral performance made in a concert hall can lead to a strong illusion of sitting in the actual space. This experience might help the listener involved in the music more deeply compared with listening to a mono recording of the same music made in dry studio because the concert hall is a place specifically designed for people to visit to listen to such kind of music.

Some researchers exclusively distinguish presence from INV and IE (Agrawal et al., 2020; Jennett et al., 2008; Nilsson et al., 2016). For example, Jennett et al. (2008) and Agwaral et al. (2020) use double dissociation examples to distinguish presence from IE, e.g., listening to electronic dance music in mono can be a highly immersive experience, but does not necessarily foster presence due to a lack of spatial cues; listening to a three-dimensional recording of restaurant ambience can induce a high level of presence but might not be immersive. However, the implicit assumption of these examples seems to be that IE is only to do with INV, and PP is purely a sensory phenomenon. The importance of considering both perceptual (sensory) and cognitive (narrative) aspects in the conceptualisation and evaluation of IE has been pointed out in previous studies (Berkman \& Akan, 2019; Calleja, 2007; Ermi \& Mäyrä, 2005). 
Based on the current model, the dance music example is a case of an IE with a high level of INV and a low level of PP. However, PP can also occur through the narrative of the music and an imagination (Ermi \& Mäyrä, 2005; Ryan, 2003). Furthermore, the overall level of the IE (OLIE) might become higher if the music was produced using a 3D virtual acoustics technology, where the sensory simulation helps listener feel like listening to the music in a club, which would put the music into a related environmental context. The increased level of PP could also enhance INV (Ryan, 2003). 3D restaurant ambience is indeed unlikely to be an interesting sound to most people, in which case the level of IE might be mainly determined by a high level of PP. However, subjective factors must also be considered. For example, such type of ambient sound can be highly involving and immersive to some other people, e.g., researchers studying urban soundscape.

\subsection{Engagement as the Initial Step Towards PP, SP and INV}

The term engagement is often interchangeably used with involvement. In the proposed model, however, the term is used to mean the initial stage of PP, SP and INV, based on previous studies. For example, Biocca (1997) uses the terms "sensory engagement" and "motor engagement" to describe a process towards presence. Brown and Cairns (2004) describe engagement as the first step towards engrossment (i.e., INV) and total immersion (i.e., IE). In addition, Agarwal and Karahanna (2000) consider engagement as a factor of cognitive absorption, which is essentially INV. In line with these, the current model considers engagement as a lower level concept to PP, SP and INV, thus being the initial step towards IE. Engagement per se does not directly induce IE, but it allows for PP, SP and INV, which eventually lead to IE.

The proposed model considers that sensorimotor engagement is the intersection for PP and SP. The sense of being in a VE with or without other intelligences initially requires the user's sensory channels (e.g., visual, auditory and tactile) to be engaged by the VE. However, as mentioned in Section 2.1, sensory perception in a real environment is influenced by the bodily movement (i.e., sensorimotor contingencies (SMCs)) (O’Regan \& Noë, 2001). Therefore, the user's motor engagement also needs to be considered in XR. This is particularly relevant in applications where the user can freely move around in a virtual environment (i.e., six-degreesof-freedom (6DOF)).

SP can be enhanced by mental or physical interactions between virtual self and other intelligences (Biocca, 1997) in an activity. This requires the user's mind and motor channels 
to be engaged with the VE stimuli. This type of engagement can also be seen as an element of a task/activity-based INV (e.g., tactical/performative involvement (Calleja, 2007)). Engagement with the narrative of Content is a primary condition for INV, but it can also contribute to the sense of being in the VE ((Calleja, 2007; Gorini, Capideville, De Leo, Mantovani, \& Riva, 2011; Murray, 1997; Ryan, 2003)) as discussed in Section 2.1.

\subsection{Properties of Immersive System and Content, and Subjective Factors}

Plausibility, interactivity and interestingness are proposed as three main properties of Immersive System (IS) and Content. These are influenced by subjective factors, such as internal reference, skills and knowledge, and personal preference.

Firstly, plausibility is associated with PP and SP. A high level of presence would not necessarily require the VE stimuli to be perfectly identical to the PE (Lee, 2004), but be more to do with the plausibility. Slater (2009) defines plausibility as "the overall credibility of the scenario being depicted in comparison with expectations", and considers plausibility illusion as an important condition for presence. Another good definition is found in the context of 3D audio: "a simulation in agreement with the listener's expectation towards an equivalent real event" (Lindau \& Weinzierl, n.d.). Both definitions suggest that, plausibility of the stimuli is not only determined by the technological advancement of IS, but also affected by the user's subjective internal reference about what is realistic. This is related to previous experience. For example, if the user had not previously experienced the virtual environment and objects being simulated, the VE stimuli may be perceived to be implausible initially even if the sensory simulation is of a high level. In such a case, a heavier cognitive processing in relation to the narrative of the content may be required to make sense of the unfamiliar environment.

Plausibility can also be understood as two different sub-concepts: social realism and perceptual realism, which are termed by Lombard and Ditton (1997). Social realism is about how likely the VE stimuli would occur in real life, whereas perceptual realism is about how close the implementation of the stimuli is to one's expectation if they existed in real life. Lombard and Ditton provide examples: a science fiction film may have a low level of social realism but a high level of perceptual realism because objects and people in the film are unlikely to exist in real life but the visual representations are perceptually realistic, e.g., using an advanced computer graphics technology. Conversely, objects and people in an animation may be high in social realism but low in perceptual realism. From this point of view, plausibility is considered to be a property of not only IS but also Content. 
Interactivity serves both SP and INV if IS and Content foster task or motor engagement. Consider that two people are playing a tennis doubles match in a VR game. The game is inherently interactive, but the levels of SP and INV might be boosted if the game console and controllers support motion tracking and tactile feedback (e.g., Nintendo Wii), compared to playing the game on a desktop computer using joysticks.

However, the barrier for SP and INV would be the players' playing skills and knowledge about the rules of the game. If they are highly skilled and experienced players, the levels of SP and INV will potentially be higher. However, beginners who might not be able to concentrate on the game itself, thus leading to low SP and INV even though PP from the sensory simulation is high. Hence, the proposed model suggests that INV and presence can be influenced by both IS and Content. This contrasts Slater (2003)'s notion sthat INV is only to do with Content.

It is also important to note that both plausibility and interactivity are bound to the SMCs supported by IS. the system's ability to dynamically render the virtual auditory-visual scene (e.g., orientation, size and loudness of the virtual stimuli) according to the user's headorientation, position and distance from the virtual objects would be of paramount importance for making sense of the environment (Martens \& Cohen, 2020; Slater, 2009). The predictability of the movement-coupled changes in the sensory simulation creates a conscious experience of a simulated environment that obeys rules in ways that would be expected in an actual physical environment (Martens \& Cohen, 2020). Consider a XR system that renders visual images in 6DOF, but provides only static and monophonic auditory images. This will lead to an incongruency between the auditory and visual perceptions, which would likely decrease not only the plausibility of the environment, but also the user's ability to quickly respond to the stimuli in the environment (e.g., in a VR battlefield game, the user is not able to quickly localise and respond to an enemy in the back due to the limited field of view and the non-directional gunshot sound.). In addition, the SMCs afforded by the VR system can also influence how realistically the user behaves in the virtual environment (Slater, 2009).

Lastly, as mentioned earlier, narrative engagement for INV and PP are essentially to do with how interesting or meaningful the content is to the user, which is a matter of personal preference. Nevertheless, it is proposed that the interestingness of Content can be enhanced by IS. For instance, consider a person who does not have much interest in animals. If a documentary film about wild life in Africa is seen on TV, the person would likely switch the 
channel or watch it only passively. The relatively plain narrative of the film might be another reason. However, if the film is watched with a VR HMD with an advanced 3D sound system, the same person may find the story about wild life more interesting because of the compelling and realistic sensory simulation of the animals and the surrounding grand nature. This may eventually lead the person to be deeply involved in the events within the film as well as feeling present. This example might also imply that a personal preference on specific content can be changed or newly developed through an immersive experience.

\subsection{Overall Level of Immersive Experience}

The current model assumes that IE can be graded, therefore quantifiable. This is based on the fact that a majority of studies on presence, narrative engagement and involvement use questionnaires with grading scales, e.g., (Busselle \& Bilandzic, 2009; Jennett et al., 2008; Lombard \& Ditton, 1997; Qin, Patrick Rau, \& Salvendy, 2009; Schubert et al., 2001; Slater \& Usoh, 1993; Witmer \& Singer, 1998). It is also hypothesised that the overall level of IE (OLIE) can be determined by the (weighted) sum of the individual levels of PP, SP and INV. This is in line with the SCl-model of immersion by Ermi and Mäyrä (2005) suggesting that the sum of the levels measured for sensory, challenge-based and imaginative immersion can represent the overall level of immersion in digital games. From a questionnaire survey, they found that the levels of the three types of immersion varied considerably for different types of video games. In a similar manner, it is expected that the levels of PP, SP and INV will vary significantly for different types of XR content in association with the level of technology. For example, watching a $360^{\circ}$ landscape of grand nature in VR could provide a high level of PPinduced IE, but the levels of SP and INV might be relatively low due to the likely lack of social interaction and intriguing narrative. In this case, the content does not have a full potential to produce a highest possible OLIE.

It is considered that OLIE would reach its highest possible level if all three components of IE achieved the highest possible levels individually. However, it is also hypothesised that the relative weighting of each of PP, SP and INV in determining OLIE would vary depending on the type of Content. This requires systematic quantitative studies in the future. Nevertheless, an example scenario for OLIE is provided as follows. Consider a boy who experiences a sense of being transported into a virtual Disney story world using a 6DOF VR system. He is surrounded by buildings and the sound of a theme song from a Disney animation film he has watched previously (i.e., internal references). The audio-visual representation of the VE is highly plausible (i.e., high perceptual realism), and he is instantly intrigued by the VE as he is 
originally a fan of Disney stories. At this stage, the level of PP would be very high due to the strong sensory and narrative engagement, and he would also start being involved in the virtual world. This is an immersive experience, but OLIE would be only intermediate at maximum since there is no social interaction or mental/physical involvement in an activity yet. Now, the boy starts exploring the virtual world, teleporting himself to different areas and trying to see what is happening. The level of PP would be enhanced due to the sensorimotor contingencies (e.g., 6DOF motion and head tracking) provided by the immersive system. He hears some loud noise from a building on his left, which he can localise accurately owing to a motion/headtracked 3D audio. Now he enters the building and sees Mickey Mouse, Donald Duck and many of his favourite animation characters singing and dancing with other children. They look so realistic perceptually that he feels like being physically with them in the house. At this stage, he would experience the initial stage of social presence. The Disney characters come and say hello to him, ask his name, and invite him to join the party. He is now physically and mentally interacting with the virtual beings and environment, which would lead to a high level of social presence, becoming more deeply involved. Eventually, he gets to feel as if he is a member of the story world (i.e., self presence), forgetting about the real world and losing the sense of time. This would certainly be a highly immersive experience overall since all of PP, SP and INV levels are at their maximum. Watching a Disney animation on TV might still provide an IE owing to the interesting narrative of the story. However, it would not be as intense as it can be as in the above example, due to the relatively low level of presence and the lack of social interaction not allowing for a complete dissociation from the physical world.

It is also important to consider an augmented reality (AR) application scenario. Using modern technologies, virtual objects can be displayed over AR glasses or a mobile device screen and their positions can be dynamically rendered according to the changes of the user's position and orientation in 6DOF in the real environment. Consider a scenario where a holographic rock band appears in a real room and surrounds the user. The audio and visual of the band members are dynamically rendered in 3D according to the user's position. Depending on the plausibility of the simulation of the virtual band, the initial stage of social presence (i.e., copresence) would be induced. The user might get more involved in exploring the band while listening to their performance from various spatial perspectives. A higher level of social presence as well as INV might be fostered if the user sings or plays an instrument along with the performance of the band. This might also boost self presence, eventually increasing OLIE. However, it is not clear whether PP is relevant in this kind of scenario since the user stays in the physical world. Research is required in this topic. It may be possible that a certain level of 
PP is produced in a similar way that one feels PP while reading a novel (i.e., narrative transportation (Green \& Brock, 2000), narrative immersion (Ryan, 2003)); by being deeply involved with the virtual band members through both mental and physical engagement, the user might lose the sense of the real world and feel that he or she is performing on the stage in a concert even if there were no visual simulation of the space provided.

\subsection{Relationship among OLIE, QoE and Flow}

Quality of experience ( $Q \circ E)$ is a popular measure that is used to evaluate the level of user satisfaction with a product or service. It is important to distinguish between OLIE and QoE. QoE is essentially about enjoyment and preference. IE can bring enjoyment, but can also lead to negative emotional responses as mentioned in Section 2.3. Therefore, a high level of IE does not necessarily mean a high level of QoE. This was also the reason why the concept of flow was not included in the current IE model. If a certain system provided the user with the feeling of a flow state, this could lead to a high QoE. However, a high OLIE does not guarantee either a flow state or a high QoE. Therefore, it is proposed that all of these constructs need to be measured separately and their correlations depending on the context are studied.

\section{CONCLUSIONS}

This paper first discussed the multidimensionality of immersive experience and explicated the concepts of presence and involvement. From this, a new conceptual model of immersive experience (IE) for extended reality was proposed. The summary of the model is as follows. IE has three main dimensions: physical presence (PP), social/self presence (SP) and involvement (INV). It is initially facilitated by the sensory stimulation of immersive system, but can also involve cognitive aspects such as attention and imagination. SP is a sense of being there with other virtual intelligences or objects and/or an experience of becoming a virtual self (e.g., one of the musicians or the conductor). Social presence and self presence are closely related to each other, hence classified as one dimension. INV is an underlying concept for a IE induced by the narrative of the content or through a certain task or activity. PP, SP and INV influence each other and collectively contribute to the overall level of IE. PP and SP necessitate sensory engagement as an initial step and require the plausibility of the sensory information provided by the system and content. This can be influenced by the system user's internal reference about what is realistic. SP and INV commonly require task or/and motor engagement, served by the interactivity of the system and content. Related subjective factors 
and barriers for this are user's skills and knowledge. INV and PP both require a certain level of narrative engagement, which is related to the interestingness of the stimuli produced by the content and system. Ultimately, the overall level of IE (OLIE) is determined collectively by the sum of PP, SP and INV, depending on the application. However, the relative weighting of each construct in OLIE is considered to depend on the context, which requires systematic studies in the future. The proposed model is expected to provide a conceptual basis for a global framework of experimental design in the field of IE research.

\section{REFERENCES}

Adams, E., \& Rollings, A. (2007). Game design and development: Fundamentals of game design. New Jersey: Pearse Prentice Hall.

Agarwal, R., \& Karahanna, E. (2000). Time flies when you're having fun: Cognitive absorption and beliefs about information technology usage. MIS Quarterly: Management Information Systems, 24(4), 665-694. https://doi.org/10.2307/3250951

Agrawal, S., Simon, A., Bech, S., Bærentsen, K., \& Forchhammer, S. (2020). Defining immersion: Literature review and implications for research on immersive audiovisual experiences. Audio Engineering Society, 68(6), 404-417.

Andrews, C., Southworth, M. K., Silva, J. N. A., \& Silva, J. R. (2016). Extended Reality in Medical Practice. Physiology \& Behavior, 176, 139-148. https://doi.org/10.1016/j.physbeh.2017.03.040

Arsenault, D. (2005). DARK WATERS: SPOTLIGHT ON IMMERSION Dominic. In Game-On North America 2005 Conference Proceedings, (March), 50-52.

Berkman, M. I., \& Akan, E. (2019). Presence and Immersion in Virtual Reality. Encyclopedia of Computer Graphics and Games, 1-10. https://doi.org/10.1007/978-3-319-082349_162-1

Biocca, F, \& Delaney, B. (1995). Immersive virtual reality technology.

Biocca, Frank. (1997). The Cyborg's Dilemma: Progressive Embodiment in Virtual Environments [1]. Journal of Computer-Mediated Communication, 3(2), 0-0. https://doi.org/10.1111/j.1083-6101.1997.tb00070.x

Brown, E., \& Cairns, P. (n.d.). A Grounded Investigation of Game Immersion.

Brown, E., \& Cairns, P. (2004). A Grounded Investigation of Game Immersion. 31-32.

Busselle, R., \& Bilandzic, H. (2009). Measuring Narrative Engagement. Media Psychology, 12(4), 321-347. https://doi.org/10.1080/15213260903287259

Calleja, G. (2007). Revising immersion: A conceptual model for the analysis of digital game involvement. 3rd Digital Games Research Association International Conference: "Situated Play", DiGRA 2007, 83-90.

Carvalho, B., Soares, M., Neves, A., Soares, G., \& Lins, A. (2014). The State of the Art in Virtual Reality Applied to Digital Games: A Literature Review. (July). https://doi.org/10.13140/2.1.2439.8722

Csikszentmihalyi, M. (1990). Flow: The Psychology of Optimal Experience. New York: Harper and Row.

Cummings, J. J., \& Bailenson, J. N. (2016). How Immersive Is Enough? A Meta-Analysis of the Effect of Immersive Technology on User Presence. Media Psychology, 19(2), 272309. https://doi.org/10.1080/15213269.2015.1015740

Damasio, A. R. (1999). The feeling of what happens: Body and emotion in the making of consciousness. New York, NY: Harcourt Brace.

Diemer, J., Alpers, G. W., Peperkorn, H. M., Shiban, Y., \& Mühlberger, A. (2015). The impact of perception and presence on emotional reactions: A review of research in 
virtual reality. Frontiers in Psychology, 6(JAN), 1-9.

https://doi.org/10.3389/fpsyg.2015.00026

Eaton, C., \& Lee, H. (2019). Quantifying factors of auditory immersion in virtual reality. Proceedings of the AES International Conference, 2019-March.

Ermi, L., \& Mäyrä, F. (2005). Fundamental components of the gameplay experience: Analysing immersion. Proceedings of DiGRA 2005 Conference: Changing Views Worlds in Play, (January).

Freina, L., \& Ott, M. (2015). A literature review on immersive virtual reality in education: State of the art and perspectives. Proceedings of ELearning and Software for Education (ELSE)(Bucharest, Romania, April 23-24, 2015), (April), 8. https://doi.org/10.12753/2066-026X-15-020

Frochot, I., Elliot, S., \& Kreziak, D. (2017). Digging deep into the experience - flow and immersion patterns in a mountain holiday. International Journal of Culture, Tourism, and Hospitality Research, 11(1), 81-91. https://doi.org/10.1108/IJCTHR-09-2015-0115

Goffman, E. (1963). Behavior in public places. New York: The Free Press.

Gorini, A., Capideville, C. S., De Leo, G., Mantovani, F., \& Riva, G. (2011). The role of immersion and narrative in mediated presence: the virtual hospital experience. Cyberpsychology, Behavior and Social Networking, 14(3), 99-105. https://doi.org/10.1089/cyber.2010.0100

Green, M. C., \& Brock, T. C. (2000). The Role of Transportation in the Persuasiveness of Public Narratives. 79(5), 701-721. https://doi.org/10.1037/0022-3514.79.5.701

Hakemulder, F Kuijpers, M. M., Tan, E. S., Bálint, K., \& Doicaru, M. M. (Eds. . (2017). Narrative Absorption. John Benjamins.

Hartmann, T., Wirth, W., Schramm, H., Klimmt, C., Vorderer, P., Gysbers, A., ... Sacau, A. M. (2016). The spatial presence experience scale (SPES): A short self-report measure for diverse media settings. Journal of Media Psychology, 28(1), 1-15. https://doi.org/10.1027/1864-1105/a000137

Heeter, C. (1992). Being There: The Subjective Experience of Presence . Presence: Teleoperators and Virtual Environments, 1(2), 262-271. https://doi.org/10.1162/pres.1992.1.2.262

Jennett, C., Cox, A. L., Cairns, P., Dhoparee, S., Epps, A., Tijs, T., \& Walton, A. (2008). Measuring and defining the experience of immersion in games. International Journal of Human Computer Studies, 66(9), 641-661. https://doi.org/10.1016/j.ijhcs.2008.04.004

Lee, K. M. (2004). Presence, Explicated. 27-50.

Lindau, A., \& Weinzierl, S. (n.d.). Assessing the plausibility of virtual acoustic environments. (c), 1187-1192.

Lombard, M., \& Ditton, T. (1997). At the Heart of It All: The Concept of Presence. Journal of Computer-Mediated Communication, 3(2). https://doi.org/10.1111/j.10836101.1997.tb00072.x

Martens, W. L., \& Cohen, M. (2020). Spatial soundscape superposition, Part I: Subject motion and scene sensibility. Acoustical Science and Technology, 41(1), 288-296. https://doi.org/10.1250/ast.41.288

McMahan, A. (2013). Immersion, engagement, and presence: A method for analyzing 3-d video games. The Video Game Theory Reader, (May), 67-86. https://doi.org/10.4324/9780203700457-10

Michailidis, L., Balaguer-ballester, E., He, X., \& Balaguer-ballester, E. (2018). Flow and Immersion in Video Games: The Aftermath of a Conceptual Challenge. 9(September), 1-8. https://doi.org/10.3389/fpsyg.2018.01682

Minsky, M. (1980). Telepresence. Omni, 2, 45-51.

Mirvis, P. H. (1991). Flow: The Psychology of Optimal Experience. Academy of Management Review, 16(3), 636-640. https://doi.org/10.5465/amr.1991.4279513

Murray, J. (1997). Hamlet on the Holodeck: The Future of Narrative in Cyberspace. 
Cambridge, MA: The MIT Press.

Nilsson, N. C., Nordahl, R., \& Serafin, S. (2016). Immersion revisited: A review of existing definitions of immersion and their relation to different theories of presence. Human Technology, 12(2), 108-134. https://doi.org/10.17011/ht/urn.201611174652

O'Regan, J. K., \& Noë, A. (2001). What it is like to see: A sensorimotor theory of perceptual experience. Synthese, 129(1), 79-103. https://doi.org/10.1023/A:1012699224677

Oh, C. S., Bailenson, J. N., \& Welch, G. F. (2018). A systematic review of social presence: Definition, antecedents, and implications. Frontiers Robotics AI, 5(OCT), 1-35. https://doi.org/10.3389/frobt.2018.00114

Qin, H., Patrick Rau, P. L., \& Salvendy, G. (2009). Measuring player immersion in the computer game narrative. International Journal of Human-Computer Interaction, 25(2), 107-133. https://doi.org/10.1080/10447310802546732

Ragan, E., Sowndararajan, A., Regis, K., \& Bowman, D. A. (2016). The Sense of embodiment in Virtual Reality. Presence: Teleoperators \& Virtual Environments, 25(2), 81-107. https://doi.org/10.1162/PRES

Ratan, R. (2012). Self-presence, explicated: Body, emotion, and identity extension into the virtual self. Handbook of Research on Technoself: Identity in a Technological Society, (October), 321-335. https://doi.org/10.4018/978-1-4666-2211-1.ch018

Ryan, M. L. (2003). Narrative as virtual reality: Immersion and interactivity in literature and electronic media. Baltimore, MD, USA: The Johns Hopkins University Press.

Sanders, T., \& Cairns, P. (2010). Time perception, immersion and music in videogames. Proceedings of the 2010 British Computer Society Conference on Human-Computer Interaction, BCS-HCI 2010, 160-167. https://doi.org/10.14236/ewic/hci2010.21

Schubert, T., Friedmann, F., \& Regenbrecht, H. (2001). The experience of presence: Factor analytic insights. Presence: Teleoperators and Virtual Environments, 10(3), 266-281. https://doi.org/10.1162/105474601300343603

Sheridan, T. B. (1992). Musings on Telepresence and Virtual Presence. Presence: Teleoperators and Virtual Environments, 1(1), 120-126. https://doi.org/10.1162/pres.1992.1.1.120

Slater, M. (1999). Measuring Presence: A Response to the Witmer and Singer Presence Questionnaire. Presence: Teleoperators and Virtual Environments, 8(5), 560-565. https://doi.org/10.1162/105474699566477

Slater, M. (2003). A Note on Presence Terminology. Pres. Connect, 3, 1-5.

Slater, M. (2009). Place illusion and plausibility can lead to realistic behaviour in immersive virtual environments. Philosophical Transactions of the Royal Society B: Biological Sciences, 364(1535), 3549-3557. https://doi.org/10.1098/rstb.2009.0138

Slater, M., \& Sanchez-Vives, M. V. (2016). Enhancing our lives with immersive virtual reality. Frontiers Robotics Al, 3(DEC), 1-47. https://doi.org/10.3389/frobt.2016.00074

Slater, M., \& Usoh, M. (1993). Presence in immersive virtual environments. 1993 IEEE Annual Virtual Reality International Symposium, 90-96. Publ by IEEE. https://doi.org/10.1109/vrais.1993.380793

Slater, M., \& Wilbur, S. (1997). A framework for immersive virtual environments (FIVE): Speculations on the role of presence in virtual environments. Presence: Teleoperators and Virtual Environments, 6(6), 603-616. https://doi.org/10.1162/pres.1997.6.6.603

Steuer, J. (1995). Defining virtual reality: Dimensions determining telepresence. In F. Biocca \& M. R. Levy (Eds.), Communication in the age of virtual reality (pp. 33-56). Hillsdale, $\mathrm{NJ}$ : Laurence Erlbaum Associates.

Tussyadiah, I. P., Wang, D., Jung, T. H., \& tom Dieck, M. C. (2018). Virtual reality, presence, and attitude change: Empirical evidence from tourism. Tourism Management, 66, 140154. https://doi.org/10.1016/j.tourman.2017.12.003

Witmer, B. G., \& Singer, M. J. (1998). Measuring presence in virtual environments: A presence questionnaire. Presence: Teleoperators and Virtual Environments, 7(3), 225- 
240. https://doi.org/10.1162/105474698565686

Zhang, C., Perkis, A., \& Arndt, S. (2017). Spatial immersion versus emotional immersion, which is more immersive? 2017 9th International Conference on Quality of Multimedia Experience, QoMEX 2017, (March 2020).

https://doi.org/10.1109/QoMEX.2017.7965655 